\title{
Focal Dental Diagnostic in Patients with Replaced Renal Function-One New Method in Dentistry
}

\author{
Maria Dencheva, Angelina Kisselova, Assya Krasteva, \\ Tsvetelina Georgieva, Iliyana Stoeva and Teodora Bolyarova \\ Medical University Sofia, Faculty of Dental medicine, \\ Medical University Plovdiv, Faculty of Dental medicine, \\ Bulgaria
}

\section{Introduction}

Patients with chronic renal disease CRD grow up in worldwide and Bulgaria makes no exception from this tendency. The people in ERSD increase too, and they require renal replacement therapy-hemodialysis or renal transplantation. With development of transplantation medicine these patients hope for better treatment and better quality of live.

In the end of the year 2009 FDM Sofia win a project which is financed by National Science Fund. This project is built on the PhD thesis of Dr. Maria Dencheva from FDM. So The Faculty of Dental Medicine (FDM), Sofia has been established as a leading scientific unit in the diagnostics and treatment of dental foci from the maxillofacial area of patients with progressive renal deficiency. The funding of various organizations proved fruitful in order for a team of experts to share their efforts and experience within the project, and also to move towards dental treatment of a much larger group of patients on hemodialysis and renal transplantation.

The objects of the project are to optimize the complex dental foci diagnostic and treatment of the patient on hemodialysis and renal transplanted and to prove the needs for prevention against fields of disturbance (dental foci) with the groups of patients formed under the project.

We are orientated to complex foci diagnostics of the field of disturbance in MFA by this population of patients, because that give to us possibility for registration not only carieses and periodontal diseases, but also energetic unintegrated areas in organism. They are not obligatory limited in tissue but they can stimulate negative the system common reactivity (SCR) and in this way to different nerve-vegetative reactions.

The complex focal dental diagnostic is as a result of a common scientific work of many years and medical specialists. The method is scientific defended and it practices from Prof. Kisselova in the Faculty of Dental Medicine Sofia. We modify it for the needs of patients on hemodialysis and kidney transplanted through including infrared thermographic methods and laser equipment. So the effect is short with aseptic healing process -Fig1. 


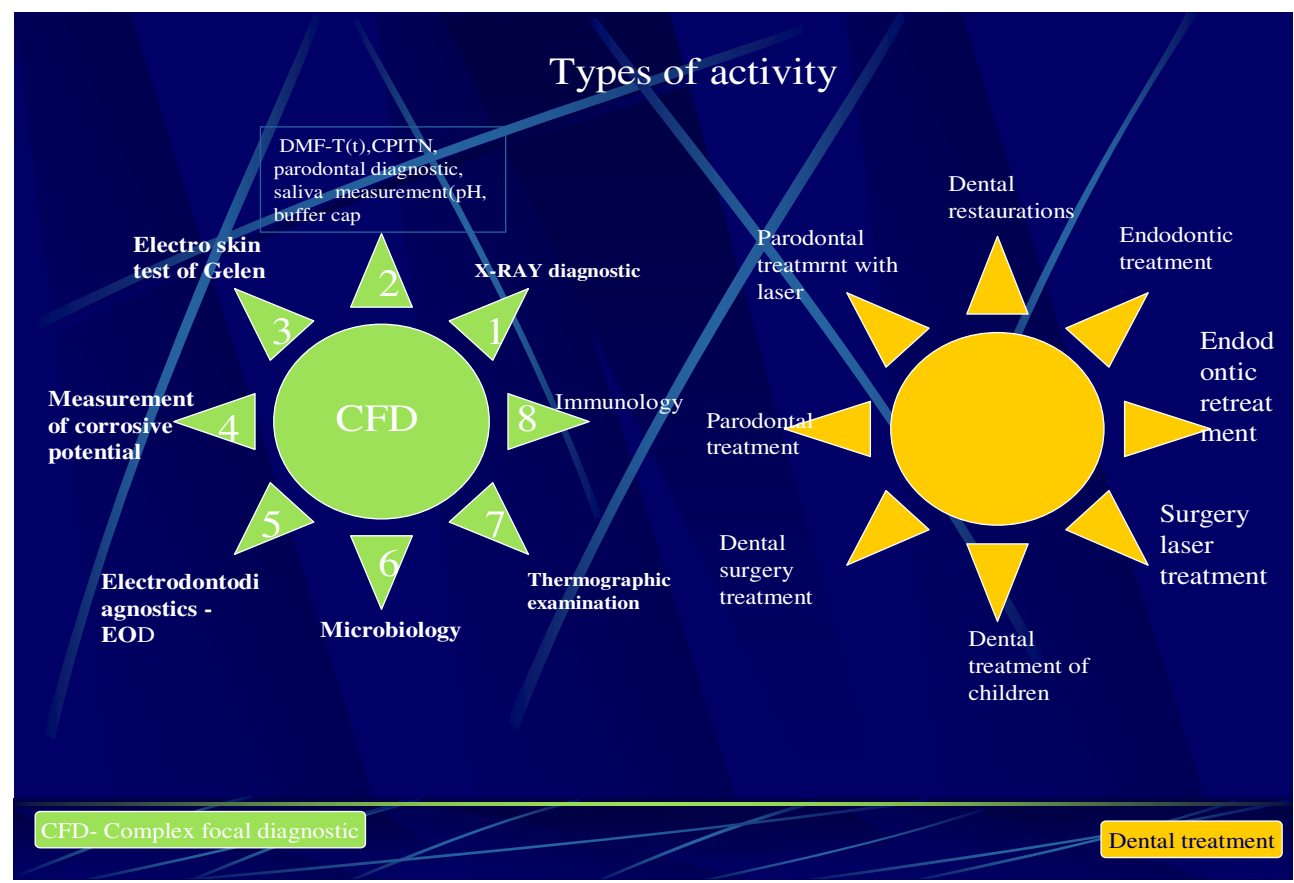

Fig. 1. Types of activity.

\section{Method description}

1. Focal directed medical history

2. Replenishment of individual diagnostic card

3. Examination of unstimulated whole saliva.

4. X-ray diagnostic.

5. Conductive methods-Electrodontodiagnostics - EOD, Measurement of corrosive potential

6. Electro skin test of Gelen

7. Thermovision research during Flir A310 in 6 six aspects.

8. Individual inquire

9. Register - The need of systematic registration of personnel diagnostics and dental treatment information, manipulation and profit of data, provides reasons to create an information system for exact analyzes and reports.

\subsection{Focal directed medical history}

The patient shall have to be asked about major diseases of the vital human systems, thus paying attention to certain reactions of a neurological- vegetative type in order to evaluate the general status of information. Medically compromised patients form a group one out of three patients that have to undergo a similar anamnesis directed straight against the source of information. Patients, who suffer from malfunctions of the immune system and changes of general reactivity, i.e. when their organism does not react adequately to minimum disturbances. In this sense any pathological process of the dental-jaw system - inflammatory 
and degenerative disease of the dental pulp, periodontitis, oral mucousis - all these could be a cause for infirmities of certain organs by the connecting tissue that links them (Kisselova-Janeva, 2001).

System for general reactivity (SGR) is defined as a functional complex by Pischinger (Fig. 2)

1. Basic substance including extra- cellular fluids.

2. Cells of connective tissue.

3. Functional peripheral vascular system.

4. Neuro-vegetative bifurcations/endings.

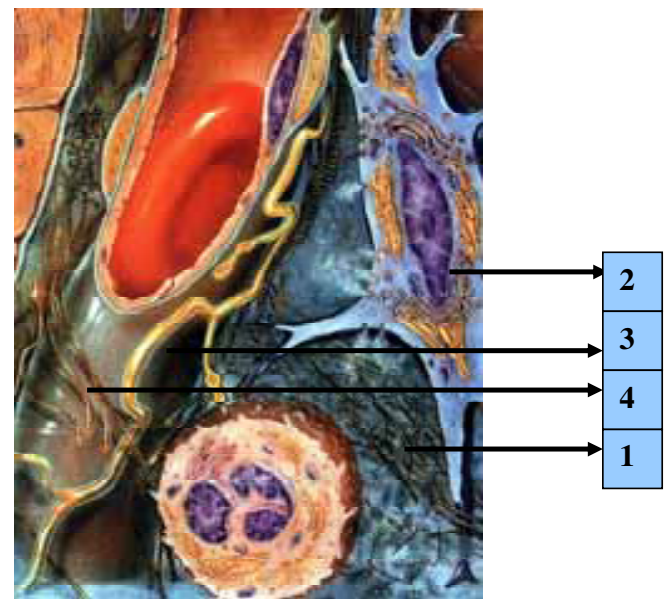

Fig. 2. System of general reactivity according to Pischinger.

The system of basic regulation nets the entire organism and represents its anatomicphysiological base. The inflammatory processes are, therefore, stirred. There appears an interjection, interacting and mutual simultaneous support of existing pathological processes, based upon exogen and endogen noxes. Via their unspecific parameters, SGR reacts according to any stimulate both locally and totally. The reactions differ according to the impulse, which is often inadequate according to the power of vexation. A most important peculiarity of the SGR is that it can react as per the vexation (left, right) whereof the injury is harder. Sources of inflammation arising from dental problems are just a part of the capabilities of the human body proves that $80 \%$ of them are located in the oral cavity (Bergsmann, 1973).

Based upon the most modern opinions regarding the inflammatory problem, the Bulgarian scholars Gerassi \&Kiselova use the following definitions:

FIELD OF DISTURBANCE- energetically non- integrated part of the organism that is transformed into a source of functional disturbances that may, but not necessarily, have material fixations. The field of disturbance by means of its constant activity and influence over the system of basic organism regulation leads to certain structural changes within.

The term INFLAMATORY is specifically concerned with material findings and their impact and that is why it is considered incomplete.

The fields of disturbance can be active and potential (latent) (Kisselova-Yaneva, 2001).

Active are those that overwhelm the local reactive barrier and, as a result, there is a distant commencement influence over the general organism reactivity. 
They may be within a compensation period without any clinical manifestation, so that only the data from different tests or the decompensate period of single symptoms can reveal the overall clinical picture.

The potential are chronically restricted information alterations whereas the local protective barrier is still intact, thus there is no distant disturbance. A number of patients are carriers of latent fields of disturbance, yet even a banal infection can lead to a trigger for inflammatory activity. The disturbances that infections and inflammation cause to the organism can be of paramount importance in life threatening situation.

The fields of disturbance may be present in any part of the organism.

The diagnostics of the fields of disturbance (FD) is of paramount importance in order to find out the domination lines. The domination field is the one that influences most the pathogenesis of the inflammatory disease (Kisselova-Yaneva, 2001). People, seemingly of good health, do possess latent fields of disturbance, yet even a banal infection can unlock inflammatory activity.

Thus, the theory of Pischinger on the system of general regulation and the paramount importance of inflammation of infection, being etiological factor for the immergence of the chronic overload syndrome (Kisselova-Yaneva, 2002, Part1 and 2, Kisselova-Yaneva, 2000), lead to an accent over their early detection concerning each one of the patients. Inflammation sources have multilateral impact over the organism, Fig. 3.

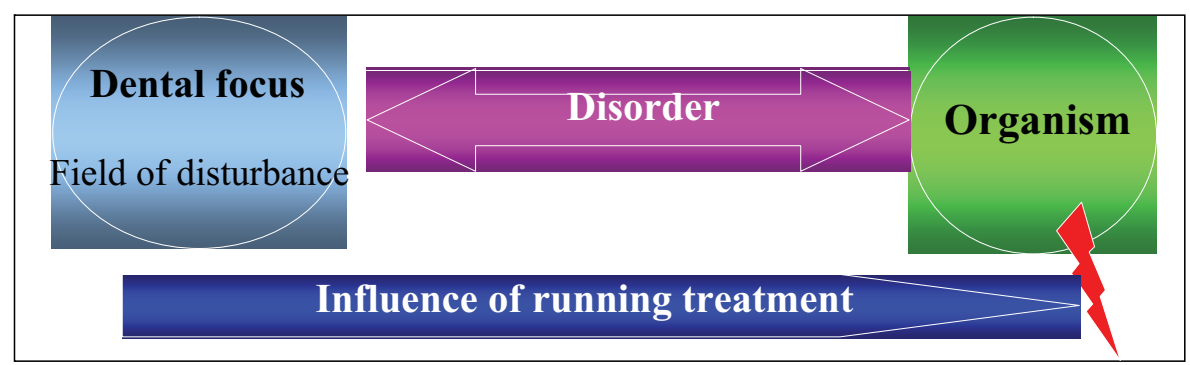

Fig. 3. Interconnection between "field of disturbance - organism".

It is a fact that the fields of disturbance can cause a disease process but, on the other hand, they can fail or seriously deteriorate the healing process by an infection process, blocking basic vital functions ( Kisselova-Yaneva,2000).

Defining of obvious fields of disturbance in the maxillofacial area is the basis of a rational plan for dental treatment, combined with the schedule of prophylactic examination considering the general state of the organism, diseases and medication therapy of each patient.

Patients, suffering from a chronic renal insufficiency are just apt to micro- inflammations as a result of the uremia (Graig et al., 2007).

Inflammation, according to Scannapieco et al. (2008), Suzucki \& Chialastri (2007), is considered a significant factor within the development of renal diseases and rejection of renal grafts. Gluhovschi et al. (2003), however, researches dental inflammation and the development of glomerolonephritis, taking into consideration the presence of other inflammatory processes. The facts present, however, are bifocal. Following antibiotic treatment and dental aid, there is a significant decrease of blood-urea and proteinuria, according to statistical data. There are some patients, who demonstrate indications 
following treatment, where the above quoted indications have increased despite antibiotic treatment, which means that the interrelation between existing dental focuses and kidneys remains uninterrupted. On the other hand, Hujoel et al. (2001) suggest that the lack of higher risk of infections in patients with coronary- cardiac diseases and radically elimination inflammations of dental origin or untreated periodontitis are not to undergo more extensive treatment. Niderhagen et al., 2003 state that afore dental sanitation, patients with liver transplants need a series of tests in order to examine the oral cavity for fields of disturbance, backing up the opinion for a necessary dental extractions with periepical changes combined with the feeling of pain and other symptoms. Non-erupted teeth without inflammation, teeth with not exactly filled root channels and caries teeth should not be extracted. Osano et al. (2005), while studying asymptomatic post-endo-dental periepical alterations and the cases of infectious complications during the anti-leukemia chemotherapy with patients with malignant blood diseases, do not observe any interrelation, paying attention to the fact that there should be an optimum strategy developed: either endodontic treatment or antibiotics. The purpose is to minimize oral complications within the period of extensive immune suppression. Meyer et al. (1999) are absolutely positive in their research, stating that the patients in an end phase of cardiac insufficiency expecting transplantation shall not be subject of "vigorous" dental treatment, since they have found no connection between the mortality rate and the infection and the level of transplant rejection within the group of patients with dental inflammation and the group without focal dental infections.

According to Rustemeyer \& Bremerich, 2007, (Rustemeyer et al. 2006), (Sarachev 2006) the removal of oral septic focus by means of extraction or another form of treatment is a necessary means in order to avoid transplant failure. They explore the necessity of dental and periodontal inflammatory sanitation with patients expecting renal and liver transplantation, as well as a cardiac implant. It becomes obvious that the need for surgical sanitation is grave within the group of renal transplanted patients. Since there are no set rules for inflammatory sanitation, the authors share the opinion that patients, who are about to undergo transplantation process, shall have to have their oral cavity sanitized in order to avoid systematic and local oral complications during the post- transplant period.

There are certain information releases regarding febrility states with unclear etiology following transplantation. The lack of precise diagnostics leads to improper treatment related to unnecessary antibiotics regime. Most often the medical personnel ignores the fact that the reason lies in the oral cavity - e.g. asymptomatic periodontal changes, unerupted and semierupted molars (Fig. 4) (Helderman, 1996), (Martinez- Tirado, 1982), (Samra et al., 1986), (Zeier, 2004, Zeier \& Ritz, 2002). Barnett, 2006 expresses the opinion that it is necessary to further explore the connection between oral and systematic diseases and states. Gugenheimer et al. (2005) have completed a research proving that there are not set protocols for dental treatment of patients, who are about to undergo transplantation. Since there is no standard for dental treatment for patients before and after transplantation. Segelnick \& Weinberg(2009) describes a case of a patient, who has lost a number of options for transplantation because of untreated periodontal disease. Another important fact is that most transplantation centers offer a minimum of medical, social and psychological consultancies and even less- dental help. Only in case of infection dental help is required. Most often, it is too late to interfere, since the operation has already been planned and there is no time for optimal dental treatment. A dentist's visit and treatment has to take place log before the operation itself and not just a couple of days before, since the sanitation of the oral cavity require much more time. Segelnick\& Weinberg (2009) states that the patients 
under total dental and periodontal programs for prevention of infection in maxillo facial area shall have to undergo a quite problematic post- operational period. Djemileva, Bolyarova (2007), Bayraktar et al., (2007), Sulejmanagic et al. (2003) back up the same opinion. In Germany, the Deutche Gesellschaft für Zahn-Mund- und Kieferheilkunde (Otten, 1998) there is a protocol that separates the patients for dental sanitation before and after organ transplantation. There is an organization, established to control and motivate those patients and to report on the sanitation completed.

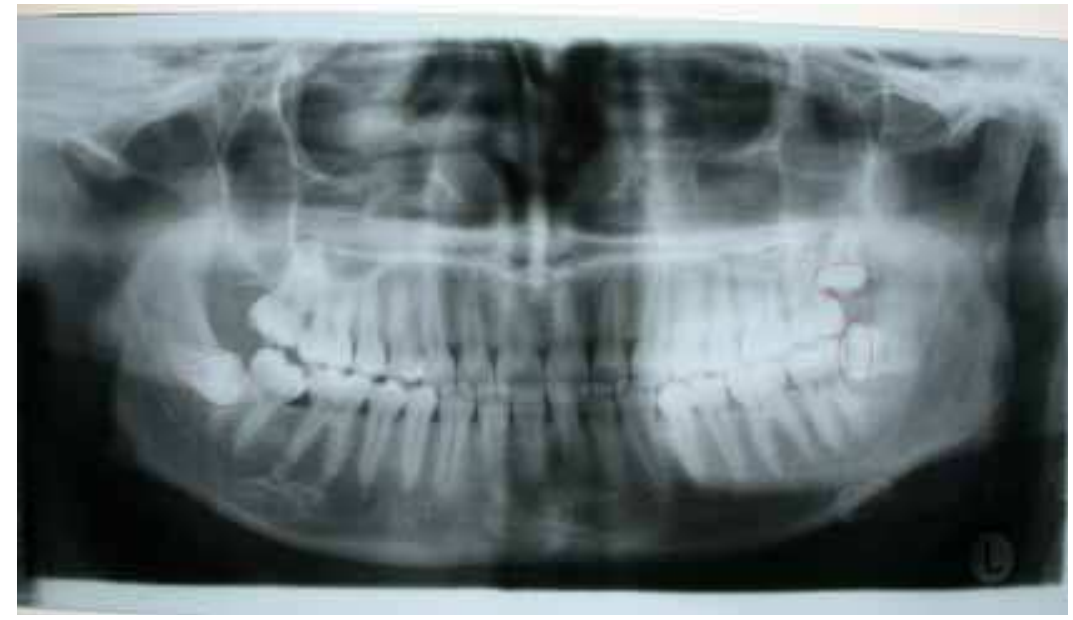

Fig. 4. Erupted and semierupted molars of a patient after a renal transplantation with a high temperature due to an uncertain reason.

The University of Old Dominion in the USA attaches a protocol of Coral Diaz(1996) for dental health during the post-transplantation period. It specifies the time for routine dental treatment, sustaining hygiene programs and first aid. The patients are distributed in three groups - one year after the transplantation, transplantation within period from one to three years and transplantations from 3 and more years. The protocol accentuates on the periodontal record of the patient.

\subsection{Replenishment of individual diagnostic card}

The individual diagnostic dental card includes the following dental and periodontal indices - DMF, PBI, PD, CPITN, OHI, and a detailed description of available dental restorative materials in the patient's mouth.

\subsubsection{Dental status and dental materials available}

DMFT- index - D - decayed, M - missing teeth, F - filling, crown.

Dental materials in patient's mouth are described by type, for example: amalgam, composite, metal alloy, ceramic, plastic, brackets, etc.

\subsubsection{Periodontal diagnostics with the following indexes - CPITN, PBI, OHI, PD}

Identification of periodontal status of participants and periodontal treatment needs by CPITN (Community periodontal index of treatment needs). 
Public periodontal index of treatment needs was established as an epidemiological tool by the WHO ( Ainamo et al.,1982)

During the clinical dental examination of patients we registered the oral status and the CPITN-index of every one of them, using a specially created index CITN probe*. Transplant patients are examined on the day of the initial visit as part of a complex focal diagnostics. Periodontal examination of patients on hemodialysis was done the day after the dialysis session in order to avoid protracted bleeding on probing. From the described methods for dental diagnostics we used the one which examined al the available teeth within the sextant. The wisdom-teeth are examined only in case of lack of molars. For the sextants in which there is a lack of at least two teeth with severe periodontitis and predict impending extraction, we used conditional code 9 .

Examined teeth in sextants:

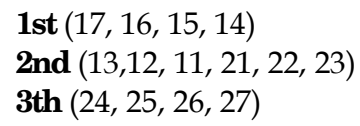

The essence of the index is described in table 1 and 2 .The most serious finding in each sextant was code in table 1 according to requirements. The maximal code, in any sextant of each patient, defined the needs of periodontal treatment (table 2).

* A specially designed CPI probe with a $0.5-\mathrm{mm}$ ball tip is used, with a black band between 3.5 and $5.5 \mathrm{~mm}$ and 8.5 and $11.5 \mathrm{~mm}$ from the ball tip.

\begin{tabular}{|l|l|}
\hline \multicolumn{1}{|c|}{ Findings } & Code \\
\hline Healthy, no signs of periodontal disease & 0 \\
\hline Bleeding observed, directly or by using mouth mirror after probing & 1 \\
\hline $\begin{array}{l}\text { Supragingival or subgingival calculus detected during probing, but all the black } \\
\text { band on the probe visible }\end{array}$ & 2 \\
\hline Pocket 4-5 mm(gingival margin within the black band on the probe) & 3 \\
\hline Pocket 6 mm or more (black band on the probe not visible) & 4 \\
\hline
\end{tabular}

Table 1. CPI.

\begin{tabular}{|c|l|}
\hline $\begin{array}{c}\text { Maximum score } \\
\text { CPITN }\end{array}$ & \multicolumn{1}{c|}{ Treatment recommendation } \\
\hline CPITN 0 & No need for additional treatment \\
\hline CPITN 1 & Need to improve personal oral hygiene \\
\hline CPITN 2 & $\begin{array}{l}\text { Need for professional cleaning of teeth, plus improvement in } \\
\text { personal oral hygiene }\end{array}$ \\
\hline CPITN 3 & Need for more complex treatment to remove infected tissue \\
\hline CPITN 4
\end{tabular}

Table 2. Treatment needs.

Defining of Hygiene index:

Dental debris is visualized by means of coloring agent. The presence $(+)$ or absence $(-)$ of debris is detected on all four dental surfaces (vestibular, oral, mezial, distal). The index is calculated in a percentage of all dental surfaces debris free. 
Defining of Papilla bleeding index (Index indicating papilla bleeding as an inflammation indicator):

By means of a periodontal probe bleeding is caused when using "sweeping" of the sulcus beside mezial and distal dental surfaces from the very base of the papilla to the top. $20-30$ seconds later the intensity of bleeding is being detected. The indications are as follow: when there is a lack of bleeding the value goes to zero " 0 "; when there are indications for single bleeding spots - "1"; indications for a narrow bleeding line at the gingivitis fringe or several bleeding spots mean -,2",; upon filling the inter-dental space with blood the extent is - „3"; at profusion bleeding,$-{ }^{\prime \prime}$.

Probing is completed by the quadrants: I quadrant - palatial, II - vestibular, III - lingual, IV - vestibular.

The index value of a patient represents an arithmetic mean of all values measured. The percentage of all bleeding papilla compared to the rest papilla defines the field of distribution of inflammation.

Defining of the periodontal depth. (PD)

The research is completed by means of a special periodontal probe (PCP-UNC 157, HuFriedy, Manufacturing Co.). The advantage of this probe is its graduation of up to $15 \mathrm{~mm}$, in an interval of $1 \mathrm{~mm}$, which grants us the opportunity to measure in high preciseness deep periodontal pockets. Measurement applies to any periodontal unit within the oral cavity at six points - central vestibular, central oral, a-medial and distal plus medial and distal - two points (vestibular and oral). Four values have been registered - vestibular, oral and a greater value for the measured medial and distal.

Defining of loss clinical attachment for each periodontal unit.

This measurement is completed once again by means of a special periodontal probe (PCPUNC 157, Hu-Friedy Manufacturing Co.). The distance between the cementoenamel junction from the bottom of the pocket of all four surfaces of each periodontal unit.

\subsection{Examination of unstimulated whole saliva}

Examination of saliva secretion assists the analysis of dental and oral health with patients of transplanted renal functions. The results of the detailed analysis of the research on saliva indicators can be utilized in the form of predilection parameters for establishing of pathological states, and therefore, to define the present dental oral status.

Patients in an end status of chronic renal insufficiency suffer from characteristic xerostomy that is easily explained by the law levels of liquid absorption, side effects of basic antihypertensive and other medicaments, possible alterations in the saliva glands because of autoimmune diseases and changes due to aging processes (Djemileva,1998), (De la Rosa Garcia et al. 2006),( Gavalda et al. 1999), (Guggenheimer \& Moore 2003), (Thelin et al. 2008). The research of Bots et al. 2007 proves that patients undergoing hemodialysis secrete less saliva (stimulated or not stimulated) temporarily, but after transplantation and reversing of the normal renal functions it is increased to its ordinary level. These same patients demonstrate a decrease in $\mathrm{pH}$ levels from 7.36 to 6.74 probably because of decrease of concentration of urea in the saliva and respectively a decrease of hydro isolation and the oral flora to ammonia (Burne \& Marquis, 2000).

According to the research of (Panov, 2010) the application of dry urine tests, studying the saliva has its information value since the percentage of positive samples reaches a value of above 50 regarding nitrites, albumen, blood and relative weight. It is a very rare event to indicate positive samples of ketones and ureabilynogene. The average situation appears with the tests for bilirubine and glucoses. Over $40 \%$ of the cases are positive regarding the 
leucocytes samples. According to research and the data accumulated by Panov we have to apply the same methods for our patients. Hereby, the research and the data of Panov make us apply the same methodology towards our patients. We use the dry tests with ten $\backslash 10 \backslash$ indicators - Deca PHAN leuco fig.5.

The conditions necessary for examination of patients incorporate the following factors: at least an hour of not consuming any food or beverages, no smoking, any form of dental and oral-hygienic procedures (brushing of teeth, mouth gargling, using of oral shower, etc.).

The standard band (sticks) is placed face down over the dorsal surface of the tongue for a period of up to 5 seconds or until it is entirely drenched. The results are recorded directly via a scale.
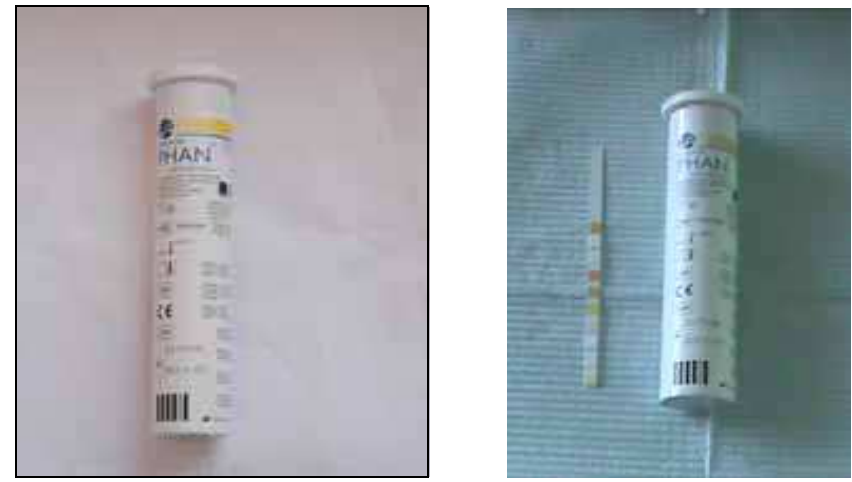

Fig. 5. Dry test sticks.

\subsection{X-ray diagnostics}

$X$-Ray diagnostics is absolutely imperative for each patient needing ortopantomography. It gives to us an initial $X$-ray structure of the maxilla-facial-area and represents an additional method indicating the presence of an active source of inflammation. Other additional methods in search of inflammation sources include:

\subsection{Conductive methods}

Electrodontodiagnostics - EOD, Measurement of corrosive potential (fig. 6 ).

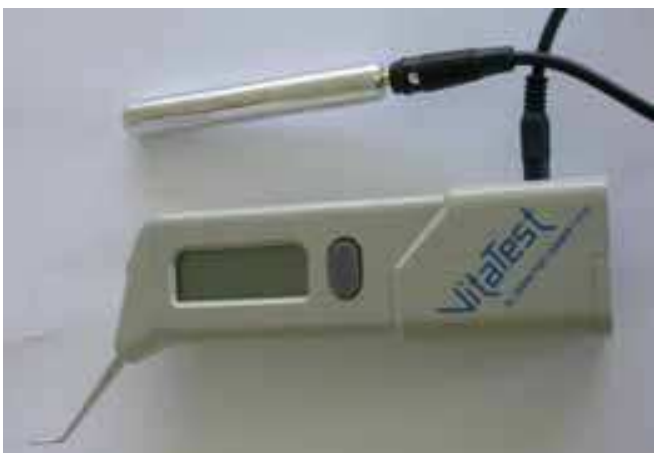

Fig. 6. Equipment for EOD examination. 
By means of "VITATEST" we examined dental vitality. It is a specialized portable apparatus for electrodontodiagnostics. Essentials of the examination: the passive electrode lies in the patient's right hand while the active one (the cathode) is placed at the characteristic spot of Rubin on the surface of a dried tooth that has to be examined. After pressing the start button the micro electrical mono-polar impulse begins to increase. When the patient reacts the active electrode is removed from the tooth. Then there is a check of the recordings displayed on the screen of the device. The following values are considered to be standard in Bulgaria:

2-6-10 $\mu \mathrm{A}$ - reaction of a normal pulpa, up to $20 \mu \mathrm{A}$ - acute caries, up to $30 \mu \mathrm{A}$ - chronic caries, up to $35 \mu \mathrm{A}$ - hyperemia of dental pulpa and partial pulpitis, from 40 - to $60 \mu \mathrm{A}-$ necrosis of the coronary pulpa, between 100 and $200 \mu \mathrm{A}$ - necrosis of dental root pulpa (Botushanov, 1994), (Kodukova et al. 1980).

Examination of corrosive potential by means of "CORPOTEST" apparatus (Fig. 7 ).

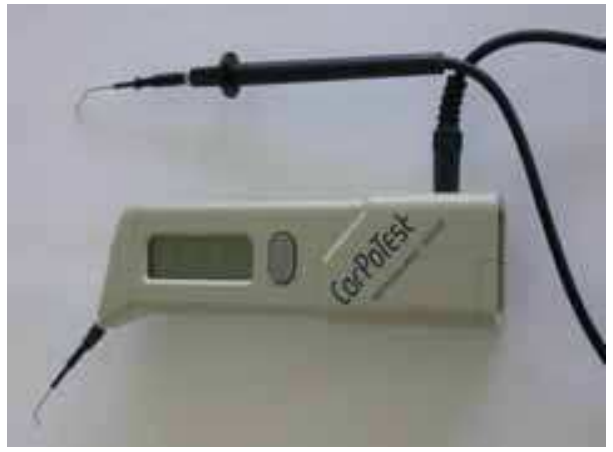

Fig. 7. Apparatus for measurement of corrosive potential.

Corpotest apparatus is essentially a direct current milivoltmeter with high input resistance of $25 \mathrm{M} \Omega \pm 5 \%$, allowing the measured electrical sources not to be loaded. It has a battery charger of $9 \mathrm{~V}$. The range of measured potential differences varies from -1990 to $+1990 \mathrm{mV}$. This test applies for all metals and alloys needed for obturations and denture constructions. Optimal values are considered to vary from 100 to $150 \mathrm{mV} /$ for each separate metal object and up to $800 \mathrm{mV}$ - total for all metal objects in the oral cavity. The measurements of alloys of non- precious metals are marked with a minus (-), for those made of precious metal with plus $(+)$ (Petrunov et al.2009).

Measurement of corrosive potential - This test studies the pathogalvanic elements in the oral cavity in case there are metal objects - amalgam obturation metal bridge constructions, metal frame of removable denture.

Patients undergoing hemodialysis need an objective and almost obligatory finding in order for the uremic breath and the changed sense of taste in the oral cavity to be registered. These are a result of the increased concentration of urea in the saliva and its consecutive transformation into ammonia (Temnyalov,2004), (Cervero et al. 2008), (Kho et al. 1999 ). It is, however, possible that such complaints be observed in patients, whose laboratory blood and urine indications are still normal, e.g. after transplantation and this is due to the increased corrosive potential combined with poor personal and professional oral hygiene (Petrunov et al.2009).

\subsection{Electroskin test of Gelen}

EST of Gelen (electro-skin test of Gelen) (Fig. 8) for defining of local reactivity is completed by means of MICRODENT apparatus. 


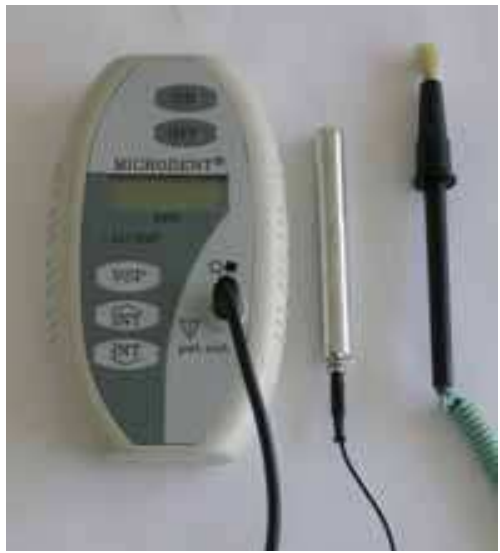

Fig. 8. Apparatus MICRODENT.

It is a specialized portable device for focal diagnostics. It is equipped with a system for graduate increase of electricity applied to the patient following interruption and post closure of the patient's circuit, thus avoiding pain during the test. The type of patient's electricity is galvanic. The input voltage varies from $3,0 \mathrm{~V}$ to $19,5 \mathrm{~V}( \pm 0,5 \mathrm{~V})$. The test's essentials consist of defining of local reactivity of the skin above the zone of the supposed or detected field of disturbance (source of infection) after a clinical examination and paraclinical tests (image diagnostics). This is done by means of subjective and objective findings. The subjective ones are registered by the patient as hyper-algesia, and the objective ones - as a hyperemic zone at or around the location of detected dental changes or adjacent dental tissues. The passive electrode of the apparatus (cathode) is held by the patient with their right hand, while the active is a small brush that is periodically moisturized with physiological solution/sodium chloride $(\mathrm{NaCl})$, moving in circles around the facial skin. In the beginning of the examination the individual limen of sensitivity of each patient is identified and it is not changed until the very end of the test procedure.

\subsection{Thermovision research in 6 six aspects}

Since any object which is higher than the absolute temperature - $273 \mathrm{C}$ emits infrared rays. Thermography is not invasive to the human body, and is a non-contact technique through which the temperature distribution of the human body surface can be monitored and recorded. In 1968 thermography was introduced as a method of diagnostic examination in the medical field (Miroshnikov 1980, Komoriyama et al. 2003).

The interest paid in the foccal infection as a "hidden" disease leading to the damage of different organs increases more and more because of the fact that patients are being directed to such an examination after all the diagnostic and therapeutic sequences have been run out - unnecessary loss of time and money. The contemporary diagnostics of foccal infection requires reducing the subjective factor in the measurement to zero. These conditions are fulfilled by thermography - contact or infrared - precise and reliable method objectively reading the changes in the temperature of definite points. In combination with the medical approach not to measure just the value of the $t^{\circ}$, but the thermoregulations capacity of the organism in dynamics, the regulation thermography is unique method for prophylaxis of foccal infection by registrating "hidden" changes.

Medical analysis of the thermogram - it is based upon leading indications: 
1. Temperature gradient - this is the quantity of temperature difference between two elements of the examined object.

Distribution of thermal emissions on the surface of human body is uneven, there exists the so called "physiological asymmetry", reasons for which is the heterogeneous structuring of the elements of the dermal system.

Clinical data indicate that the magnitude of physiological asymmetry is maximum $0,4{ }^{\circ} \mathrm{C}$. In this context the temperature gradient of up to this value is within the standard and should not be interpreted as a pathological thermal visional symptom.

\section{Qualitative characteristics of the temperature field of the object or a separate fragment}

The study of qualitative characteristics of termal distribution over the surface of the human body in the most widespread approach for evaluation of a thermogram. There are three different options for qualitative evaluation : Isothermic - when all or a predominant part of the elements of the tested object have identical or similar / within the limits of physiological asymmetry / temperature.

Hypothermia - detection of an area within the thermal field of the object with temperature less than that of the surrounding elements ; by degree of intensity the hypothermia can be : moderate / thermal gradient of up to $1,0^{\circ} \mathrm{C}$, expressed / gradient $1,0^{\circ}-2,0^{\circ} /$ and acutely expressed / with a gradient exceeding $2,0^{\circ} \mathrm{C} /$.

Hyperthermia - detection of an area within the thermal field of the object with temperature higher than that of the surrounding elements; By degree of intensity hyperthermia is graded likewise.

The laboratory for thermovision diagnostics has two separate rooms: medical office with a specific premise for the patent to stand during the examination and a room for achieving thermal adaptation / waiting room/.

Auer thermographic protocol is:

Basic requirements towards the environment in order to provide optimum conditions thermalvision diagnostics :

- $\quad$ Distance from the camera to the patient - from $0,3 \mathrm{~m}$ to $2 \mathrm{~m}$;

- $\quad$ Room temperature $-22^{\circ} \mathrm{C} \pm 2^{\circ} \mathrm{C}$;

- No air draft with seep exceeding $1 \mathrm{~m} / \mathrm{sec}$; that is why no ventilators and air conditioners are allowed;

- $\quad$ There should be no open sources of thermal radiation;

- The patient or the thermovision camera must no be exposed to direct sunlight or radiation from powerful artificial lights;

- Instruct the subject to refrain from smoking for at least $4 \mathrm{hr}$ before thermographic examination.

- No anti-perspiration fluants are allowed

In order to guarantee maximum effect and reliability of the test and to reach a state of adaptation of thermoregulatory mechanisms the patient has to wait in a room of stable temperature comfort for approximately 10 minutes while taking off thick or tight clothes and trying to relax.

To measure temperature accurately, it is therefore necessary to compensate for the effects of different radiation sources - the emissivity of the object, the reflected apparent temperature, the distance between the object and the camera, the relative humidity, temperature of the atmosphere. This is done on-line automatically by the camera.

Thermal images were produced by an infrared - Flir A310, which detects temperature differences as low as $0.06 \mathrm{C}$, and analyzed using an imaging system- ThermaCAM Researcher Professional and Therma CAM Reporter 8. 
Simultaneous photographs are taken by infrared camera a digital photo camera of the face, right and left profiles, neck, abdomen, back - static thermovision. The entire body is observed for about 5 minute. Should here be doubt for focal source additional photos are taken.

Then the data is processed by a computer and the function Fusion image applied. It is used for achieving greater specificity of the area with detected temperature discrepancy and a gradient exceeding $0,4 \mathrm{Co}$ is considered to be statistically significant and indicative for the presence of a pathological process.

In a table form the program Therma CAM Reporter 8 creates a protocol on the diagnostics. Later on the X-ray findings are compared to the Gelen test. An opinion is issued on the present active field/s of disturbance due to MFA \maxillo facial area \. Thermal findings from other organs and systems are described and if necessary the patient is transferred to an expert - e.g. consultation with an otolaryngology specialist.

Regarding the active fields of disturbance in MFA there is a treatment plan prepared.

\section{A Case}

Hemodialysis patient. The patient goes to a prophylactic dental examination without any complaints. Following the above described tests it became evident that there was hyper thermal, asymmetric field in the area of upper left molars. Following clinical examinations findings probed that there were obturations at positions 26, 27, 28. Then sector X-ray graph and EOD were applied, as well as the electrical-skin test of Gelen. In this particular case there was no correlation between the test data and the results from the test of Gelen and the infrared camera. The EOD test of the three teeth proved as follows $-12 \mu \mathrm{A}, 70 \mu \mathrm{A}, 18 \mu \mathrm{A}$. The values of tooth 27 indicate necrosis. Following endodentic treatment confirmed the diagnosis of asymptomatic pulp necrosis.

Infrared diagnostics can be applied with certain priority in the field of vascular diseases and control over the functioning of vascular fistulas in patients under dialysis Fig. 9.

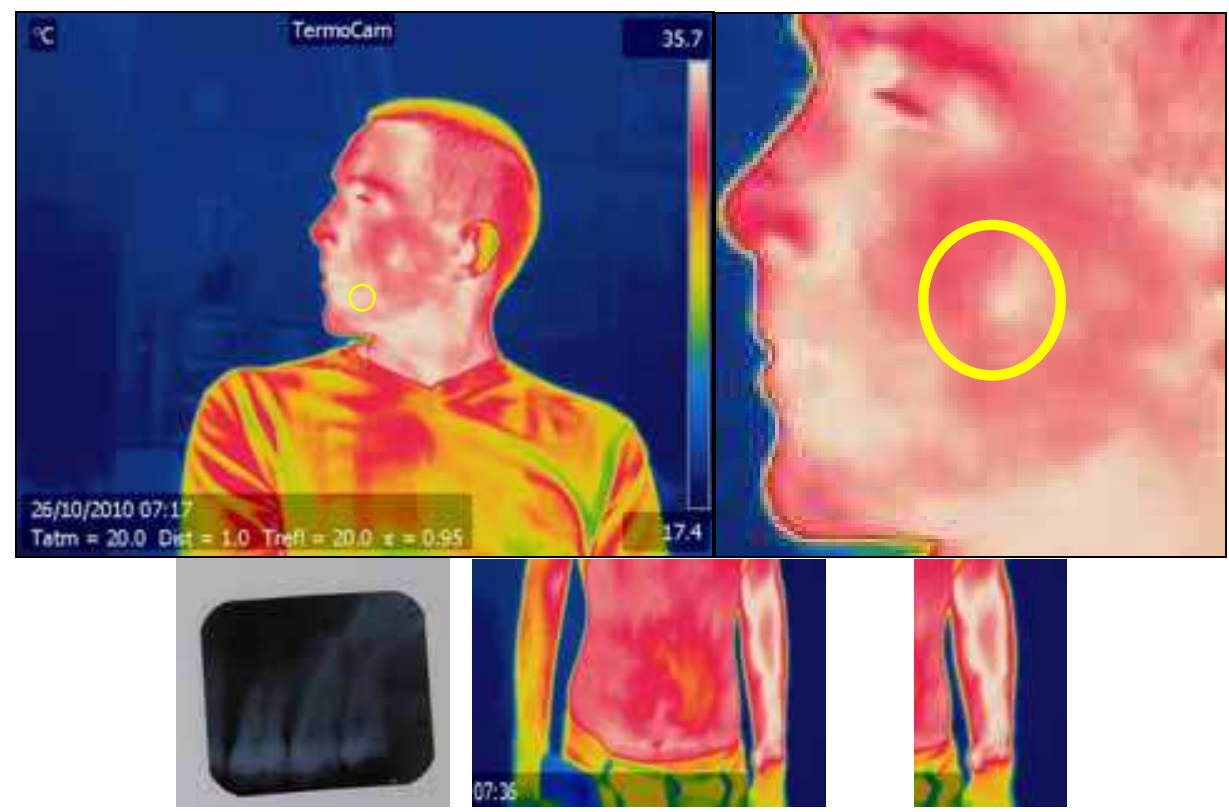

Fig. 9. Thermovision of head, arms and body.X-ray of 26,27, 28. 


\subsection{Individual inquire}

$\mathrm{Sex} / \mathrm{m} / \mathrm{f} \quad$ age.....
date...$\ldots \ldots \ldots \ldots \ldots \ldots \ldots$

Self assessment of dental health

- Very good

- Good

- Satisfactorily

- Bad

Education

- Very bad

- Basic

- Technical/Specialized

- Higher

Position towards dental health

- Dental visit only by pain and/or visible changes in maxillo-facial area

- 2 times a year

- 4 times a year

- Compliance with dental treatment plan

- Before transplantation

Did any medical person explain toYou the relationship between damaged tooth structures and common diseases?

- Yes

- No

\section{It is better to visit:}

- Private dental clinic

- A defined structur in hospitle

- Speciliced center for dental treatment of medical compromized patients

What kind of manipulations do you become in the dental office more often.

- Tartar cleaning

- Dental obturation

- Tooth extraction

- Treatment of pulpitis and periodontitis

Do you know the dental activities included from National health insurance fund (NHIF)

- Yes

- No

If you be clear about, do you mean that they are enough

- Yes

- No

What is your recommendation for enlarge of dental manipulations financed by NHIF

- Profesional dental cleaning of calculus and debrs

- More often dental examination

- Anything more (please describe)

What kind of resuorces for oral hygiene do you use

- Tooth- brush

- Tooth paste 
- Oral douche

- Mouthwash

- Dental floss

- Intertooth brush

- Cheving gum

- Bonbons without sugar

\section{How many times do you wash your teeth}

- Once

- Twice

- 3 times daily

- Do not wash every day

The data from the presented individual inquiry are comparable to the objective findings of the clinical dental examination and besides give to us a broader view on the information of these patents regarding the importance of dental health. We also seek their opinion on a better organizing of dental aid.

Based upon the research of (Dencheva, 2010) 170 patients separated in three groups: hemodialysis $(n=59)$, with renal transplants $(n=51)$ and health controls $(n=60)$ we defined the attitude of patients towards their dental health fig.10. It is an alarming fact the hemodialysis and renal transplant groups indicate the highest percentage of patients asking for dental help only after feeling pain or suffering from obvious changes in the facialmaxillary area

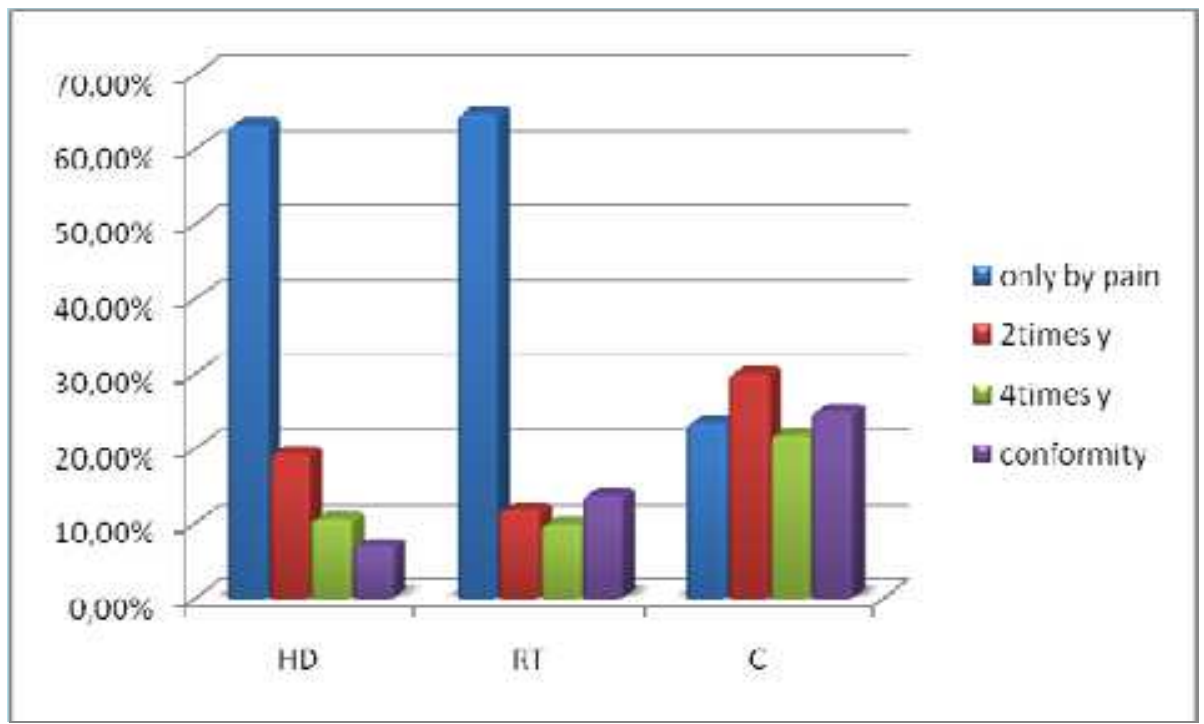

Fig. 10. Position towards dental health.

The active cooperation with all organizations of patients engaged with the problems of patients with renal transplants and those expecting other organ transplants makes us positive that the achievements of our team is of paramount social importance. 


\subsection{Register}

For the purpose a data base was created using the Access 2007 software. The created data base contains information about the patient's medical history, dental status, periodontal status, x-ray images, photos, saliva tests, preclinical examinations, dental treatment. The created data base assures an easy registration of all personnel data; permits comparison of dental status before and after dental focal infection treatment; gives possibilities to provide statistical analyzes.

The necessity for systematic accumulation together with facilitated access and processing of information for the diagnostics and treatment measures motivates the development of an information system for the needs of this scientific project.

The structure has been designed and furnished in such a way that allows the easiest possible access to the date with regard to a single patient facilitating extrication of information. Initiation platform with command keys has been developed in order to provide direct access to information on the results of separate tested indications as well as for the completed dental focal sanitation (diagnostic and treatment) of all patients in total and separately according to groups suffering from a specific disorder.

The program is capable of filing records for activities completed that can be easily selected from the main menu. The files apply for all patients as well as for each separate group as per their specific disease. It is a flexible program allowing the formation of additional requests and reports according to the needed information in concern.

The information can be easily formatted into SPSS or MS Excel, which enables us to statistically process the data and graphically display them.

The establishment of a database for patients under hemodialysis and renal transplants makes the program applicable for all other patients suffering from system diseases subject to focal dental sanation - diagnostics and treatment.

Following the final completion of the project we expect that the system database shall also become a register of the patients undergoing dialysis and renal transplants, who have been treated by means of focal dental sanitation before a forthcoming transplantation or are included in a prophylactic dental program. The information will undoubtedly be useful not only for dental specialists but also experts in the field of dialysis and experts within the field of transplantation medical science.

\section{Conclusion}

The methodology offered can be successfully applied to patients suffering from another organic chronic disease and a forthcoming transplantation operation e.g. heart valve prosthesis, liver, marrow and cardiac transplantations. Its completion determines formulating of an optimum plan for dental treatment of patients with strict succession of eliminating of active fields of disturbance of MFA Fig. 11.

So far it is a part of the current project "Optimization of the complex focal dental sanitation in patients on hemodialysis and renal transplanted.” This diagnostics methodology has been applied to 83 patients divided into two basic groups-group - hemodialysis and renal transplanted. For each of them there was a preliminary prepared focal dental schedule of treatment. 55 patients have successfully finished treatment procedures and are now a part of prophylactic dental programs for tracking a post-treatment phase $\backslash$ tracking. There is also a interim statistic phase of processing of the accumulated data. 


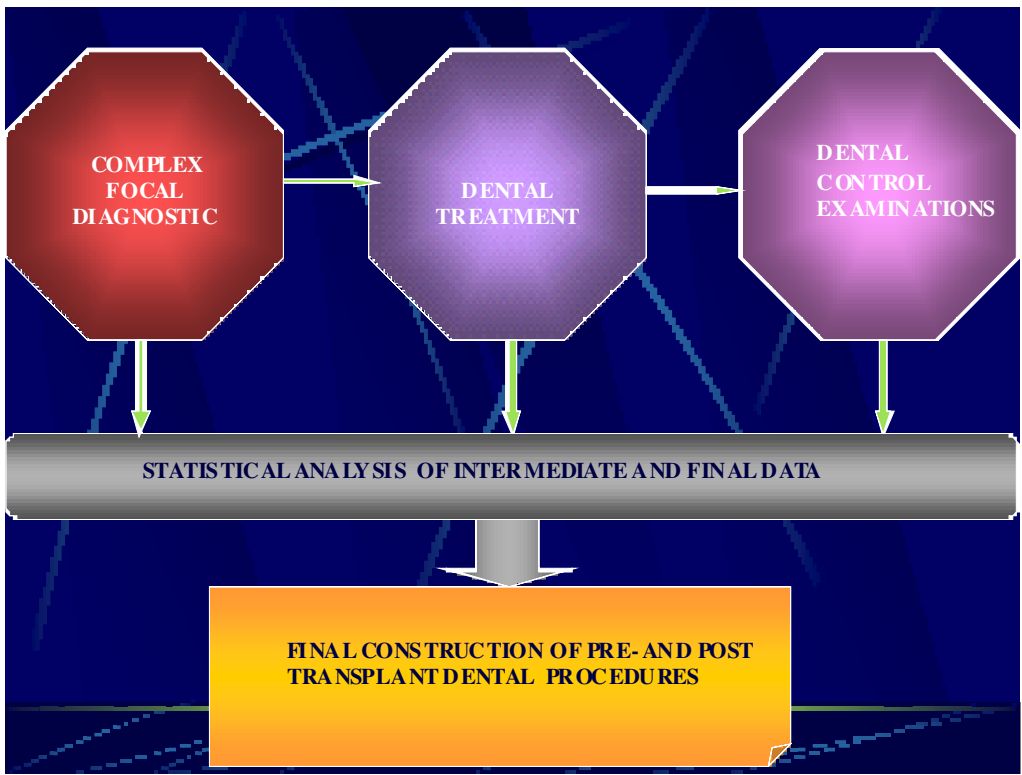

Fig. 11. The functional center of the specialized sector of dental focal diagnostics and treatment.

\section{Acknowledgment}

My deepest gratitude to Professor Angelina Kiselova for all the experience and knowledge, and assistance she shared and gave to me and last but not least to my colleagues Krasteva, Georgieva, Aleksiev, Stoeva.

\section{References}

Access 2007. Monograph, Softpres, Sofia ,160

Ainamo, cl, D. Barnes et al. (1982). Development of the World Health Organization (WHO) Community Periodontal Index of Treatment Needs (CPITN). International Dental cburnal.; 32: 281-291.

Barnett, $M$. (2006). The oral-systemic disease connection. An update for the practicing dentist. .ADA, vol. 137, 5S-6S.

Bayraktar, G., et al.(2007). Dental and periodontal findings in hemodyalisis patients. Oral Disiase; 13: 393-7.

Bergsman, O. (1973). Der Herd als pathogenetischer Faktor. Öster. Z. Stomatol. 70, № 3, 90100.

Bots, C. P., H. S. Brand, Ihg. Poorterman. (2007). Oral and salivary changes in patients with end stage renal disease (ESRD): a two year follow - up study. British dental eburnal; $10 ; 10-38$. 
Botushanov, P. (1994). Diagnostika i lechenie na vaspalitelnite zabolyavaniya na parodonta. Academica Press, Plovdiv, 247.

Burne, R. A., R. E. Marquis. (2000). Alkalai production by oral bacteria and protection against dental caries. FEMS Microbiol Lett; 193: 1-6.

Cervero, A. et al.(2008). Dental management in renal failure: Patients on dialysis. Med Oral Patol Oral Cir Bucal, 1: 13 (7): E 419-27.

De la Rosa Garcia, $E$. et al.( 2006). Oral mucosa symptoms, signs and lesions, in end stage renal disease and non end - stage renal disease diabetic patients. Med Oral Patol Oral Cir Bucal., Non 1; 11 (6): E 467-73

Dencheva, M. (2010). Focal infections in maxillo-facial area in patients on hemodialysis and renal transplanted- action algorithm, Dissertation, Sofia, 160

Diaz C., 1996. The Oral Health Assessment of Kidney Transplant Patients Undergoing Immunosuppressive Therapy. Available from

http: / /www.usc.edu /hsc /dental /dhnet /papers/coral149.html

Djemileva,T. (1998). Xerostomia.ACER.

Djemileva,T., T. Boljarova.(2007). Gingivalno razrastvane pri sistemna terapia s kaltsievi antagonisti, imunosupresori i hidantoini. „ACER", Sofia., 118.

Gavalda, C., J. Bagan, C. Scully, F. Silvestre, M. Milian, Y. Jimenez. (1999). Renal hemodialysis patients: oral, salivary, dental and periodontal findings in 105 adult cases. Oral Dis, 5: 299-302

Gluhovschi, Gh., et al. (2003). The significance of dental foci in glomerular nephropathies. Medicine and Biology vol. 10, No 2, pp. 57-61.

Graig, R., et al. (2007). Periodontal diseases - a modifiable source of systemic inflammation for the end-stage renal disease patient on hemodialysis therapy. Nephrol Dial Transplant, 22: 312-315.

Guggenheimer, J., et al., (2005). A survey of dental care protocols among US organ transplant centers. Clinical Transplantation; 19: 15-8.

Guggenheimer, L, P. Moore. (2003). Xerostomia. Etiology, recognition and treatment. $A D D A$, vol. 134.

Helderman, I H., M. Govani, T. McCurley et al. (1996). A case of lethal febrile illness in a renal transplant patient presenting after a dental visit. Nephrol Dial Transplant, 11: 1385-1387.

Hujoel, P. P., M. Drangsholt at al.( 2001). Examining the link between coronary heart disease and the elimination of chronic dental infections. eADA, vol. 132.

Kho, H. S.,et. al.(1999). Oral manifestations and salivary flow rate, $\mathrm{pH}$, and buffer capacity in patients with end-stage renal disease undergoing hemodialysis. Oral Surg Oral Med Oral Pathol Oral Radiol Endod, 88: 316-319.

Kisselova-Yaneva, A. (2001) Dental alergology and focal diagnostic. Gutenberg, Sofia., 327.

Kisselova-Yaneva., A.(2000). Stomatogenni poleta na smustenie pri nyakoi hronichni zabolyavania i alergii, Dissertation, Sofia, 480.

Kisselova-Yaneva., A.(2002). Ognishtniya problem v stomatologiyata i meditsinata-II chast. Balgarska meditsina, Znanie, Sofia,10, 5, 29-32.

Kisselova-Yaneva., A.(2002). Ognistnia problem v stomatologiata i medizinata-I hast. Balgarska meditsina, Znanie, Sofia,10, 4, 27-29. 
Kodukova, A. et al. (1980). Electrovasbudimost na intaktni zabi v razlichni vasrastovi grupi. Problemi na stomatologiata, Sofia., vol VIII: 8-14.

Komoriyama, M.,R. Nomoto et al. (2003). Application of thermography in dentistryvisualization of temperature distribution on oral tissues. Dental materials eburnal; 22(4), 436-443

Martinez-Tirado, d; J. Welchel; R. E. Lordon. (1982). Ocult Dental Infection Causing Fever. Inrenal Transplant Patients. Am J Kidney Dis; 2: 354-6.

Meyer, U. et al. (1999). Heart transplants - assessment of dental procedures. Clin Oral Invest, 3: 79-83.

Miroshnikov, M.(1980). Thermovision in medicine. Meditsinskaya Tehnika, No. 4, pp. 13-19

Niederhagen, B., M. Wolf, T. Appel et al. (2003).Location and sanitation of dental foci in liver transplantation. Transpl Int,; 16: 173-178.

Osano, $H$., et al. (2005). Odontogenic infections and septizemia in immunocompromised patients with hematologic malignancies - assessment of the need for root canal treatment in patient with leukemia. elchi Medical School eburnal, 28.

Otten, J. E.( 1998). Zahnsanierung vor und nach Organstransplantation. Wissenschaftliche Stellungnahme der DGZMK.

Panov, Vl. (2010). Oral cavity- a biosistem and a possible sourse of infectious materials. Dissertation, Varna, 189

Petrunov, B et al. (2009). Klinichna imunologia, klinichna alergologia, dentalna klinichna alergologia. Sofia, Arso,276.

Rustemeyer, $L$, A. Bremerich.(2007). Necessity of surgical dental foci treatment prior to organ transplantation and heart valve replacement. Clin Oral Invest, 11: 171-174.

Rustemeyer, J., M. Black, A. Bremerich.(2006). Stellenwert der dentalen und parodontalen Fokusssanierung vor Organtransplantationen und Herzklappenersatz. Transplantazionsmedizin, 18: 24.

Samra, Y.; Sh. Barak; Y. Shaked. (1986). Dental infection as the cause of pyrexia of unknown origin - two case reports. Postgraduate Medical eburnal, 62, 949-950

Sarachev, E .(2006) Connection between some joint diseases and foci of odontogenic origin. eburnal of IMAB - Annual Proceeding (Scientific papers), book 2.

Scannapieco, F. A., M. Panesar. (2008). Periodontitis and chronic kidney disease. $J$ Periodontal; 79: 1617-1619.

Segelnick, S., M. Weinberg, (2009).The periodontist's role in obtaining clearance prior to patients undergoing a kidney transplant. JPeriodontal; vol. 80 (6); 874-876.

Sulejmanagic, N., et al.(2003). Dental treatment in patients with kidney diseases. Acta Stomatol Croat, vol. 37, № 3.

Suzucki, $L$, S. M. Chialastri. (2007). Dental implications for the immunocompromised organ transplant patient. Grand Rounds Oral-Sys Med; 3: 36-44

Temnyalov, N.(2004). Ureata- farmacologichni, klinichni i terapevtichni aspekti. Grafic OOD, Varna, 78.

Thelin, W. R., M. T. Brennan, et al. (2008). The oral mucosa as a therapeutic target for xerostomia. Oral Diseases; 14: 683-689.

Zeier, M. G. (2004). Relapsing oligosymptomatic fever in a kidney-pancreas transplant recipient. Nephrol Dial Transplant, 19; 2665-2667. 
Zeier, M.; E. Ritz. (2002). Preparation of the dialysis patient for transplantation. Nephrol Dial Transplant, 17, 552-556. 


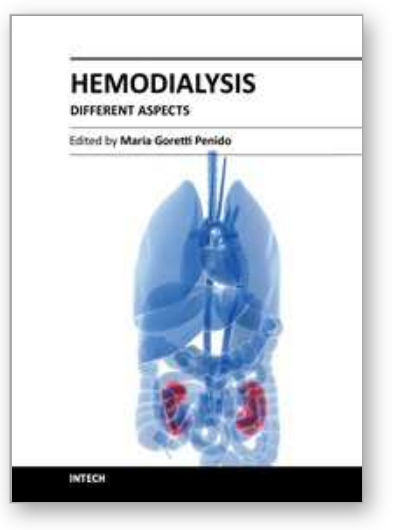

\author{
Hemodialysis - Different Aspects \\ Edited by Prof. Maria Goretti Penido
}

ISBN 978-953-307-315-6

Hard cover, 321 pages

Publisher InTech

Published online 14, November, 2011

Published in print edition November, 2011

The book provides practical and accessible information on all aspects of hemodialysis, with emphasis on dayto-day management of patients. It is quite comprehensive as it covers almost all the aspects of hemodialysis. In short it is a valuable book and an essential aid in the dialysis room.

\title{
How to reference
}

In order to correctly reference this scholarly work, feel free to copy and paste the following:

Maria Dencheva, Angelina Kisselova, Assya Krasteva, Tsvetelina Georgieva, lliyana Stoeva and Teodora Bolyarova (2011). Focal Dental Diagnostic in Patients with Replaced Renal Function-One New Method in Dentistry, Hemodialysis - Different Aspects, Prof. Maria Goretti Penido (Ed.), ISBN: 978-953-307-315-6, InTech, Available from: http://www.intechopen.com/books/hemodialysis-different-aspects/focal-dentaldiagnostic-in-patients-with-replaced-renal-function-one-new-method-in-dentistry

\section{INTECH}

open science | open minds

\section{InTech Europe}

University Campus STeP Ri

Slavka Krautzeka 83/A

51000 Rijeka, Croatia

Phone: +385 (51) 770447

Fax: +385 (51) 686166

www.intechopen.com

\section{InTech China}

Unit 405, Office Block, Hotel Equatorial Shanghai

No.65, Yan An Road (West), Shanghai, 200040, China

中国上海市延安西路65号上海国际贵都大饭店办公楼 405 单元

Phone: +86-21-62489820

Fax: +86-21-62489821 
(C) 2011 The Author(s). Licensee IntechOpen. This is an open access article distributed under the terms of the Creative Commons Attribution 3.0 License, which permits unrestricted use, distribution, and reproduction in any medium, provided the original work is properly cited. 